Volume: 1 , Issue: 1 Page: 27- 47
Euro Afro Studies International Journal ${ }^{\circledR}$

(EASIJ.COM)

\title{
Language teaching and testing - a research of using literature forms in the English Language Schoolbooks
}

\author{
Author(s), SASHKA JOVANOVSKA
}

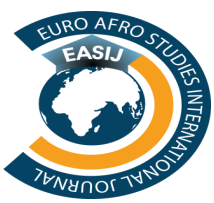




\begin{abstract}
:
The use of literature forms in the English language teaching schoolbooks is enjoying a revival for a number of reasons. Having formed part of traditional language teaching approaches, literature became less popular when language teaching and learning started to focus on the functional use of language. However, the role of literature forms in the English language teaching schoolbooks has been re-assessed and many now view literary texts as providing rich linguistic input, effective stimuli for students to express themselves in other languages and a potential source of learner motivation. The aim of my thesis is to find out if in the English schoolbooks used in some schools set by experts. Although the studies on the use of literature forms in teaching English have been increasing abroad, in our country, particularly in public schools, only English grammar is being taught. The students who are expected to memorize these rules cannot use English. The aim of this seminar paper is to exhibit why and how literature forms can be used in order to teach English effectively and efficiently. I have also compared two schoolbooks (Project 2 and Dream team 3) to see the differences between the literary content.
\end{abstract}

EASIJ

Accepted 1 December 2019

Published 5 December 2019 DOI: $10.5281 /$ zenodo.3565842

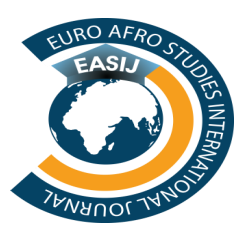


Keywords: approaches, cultural context, literature, fictions,

\section{About Author}

\section{Author(s), PhD, English Professor, North Macedonia}

(Corresponding Author) Email: saska_dimitrovska@yahoo.com

3 Euro Afro Studies International Journal ${ }^{\circledR}$ (EASIJ.COM)

Email: editor.easij@gmail.com , editor@easij.com Website: easij.com

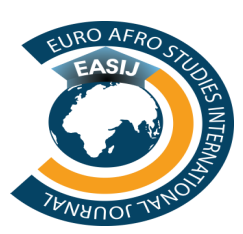




\section{INTRODUCTION}

The teaching of literature has recently been resurrected as a vital component of English language teaching. Over the past few decades, there has been much discussion on the value of attempting to teach any kind of literature, whether it is the classics or any imaginative work written in English, as part of an English language syllabus. For instance, in the sixties and seventies, there was a distinct reaction against the use of any literary English before the pendulum swung again in support of literature teaching. The opposition towards literature may well have been due to the impact of the approaches that were practiced in the decades prior to the sixties and seventies and prevailing ideas in language teaching and methodology.

\section{EDUCATIONAL FRAMEWORK FOR ELEMENTARY SCHOOLS}

In the new educational system, "Educational Framework for Elementary Schools", determined by the Ministry of Education, curriculum is understood as a means to adopt activities which are gradually joined and which create conditions to the effectual and complex use of achieved abilities and skills at the level of key competencies. These competences present knowledge, abilities, skills, attitudes and values important for personal development and use of each member of society. In the period of elementary education these are the key competencies considered: competence for learning, competence for problem solving, communicative competencies, social and personal competencies, civil competencies and work competencies.

\subsection{Textbooks in general}

Patricia determines schoolbooks in general pedagogical theory as "one kind of didactic means" (416). This author also explains how a textbook in pedagogical theory is understood. He distinguishes three basic concepts: a) textbooks as a curriculum project, b) textbook as a source of educational register for pupils, and c) textbook as didactic means for teachers (272).

\subsection{English schoolbooks}

Grant defines two different kinds of schoolbooks (12). The first type of language schoolbooks Grant calls "traditional textbooks", which are still in use all over the world, and "tries to get

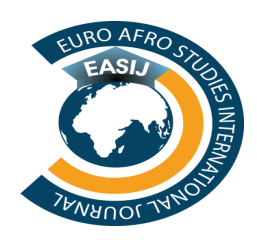


students to learn the language as a system" (12). These schoolbooks have some of these characteristics: they tend to emphasize the form, the grammar more than the communicative functions of language, they tend to focus on reading and writing activities, rather than listening and speaking activities, they emphasize the importance of accuracy, they focus narrowly on a syllabus and examinations and are highly examination-orientated.

The second type of schoolbooks, as Grant suggests, are communicative textbooks. These schoolbooks give opportunities for the students to use the language in the classroom. "These days, the word communicative is on everyone's lips. Almost every new textbook claims to be communicative" (14). Grant names the main characteristics of these textbooks. They emphasize the communicative function of language, not just the form and try to reflect the students' needs and interests, they are activity-based, they have a good balance among the four language skills, but may emphasize listening and speaking, they use the language of everyday life and encourage work in groups and pairs and finally they emphasize fluency, not just accuracy (14).

\subsection{General qualities of English textbooks}

Kitao explains some of the general qualities of a good English schoolbook. "A good English schoolbook should have correct, natural, recent, and standard English." Since students' vocabulary is limited, the vocabulary in schoolbooks should be explained or used in different contexts to help the learners' full understanding of vocabulary that they may not be familiar with. For lower-level students, grammar should also be explained. Some schoolbooks enable the learners to figure out the grammatical rule themselves by offering certain clues. Many schoolbooks use narratives and essays. It is very useful to have a variety of literary forms (for example, newspaper articles, poetry, or letters), so as students can learn to deal with different forms. Kitao points out the importance of cultural knowledge. "The cultural information included in English schoolbooks should be correct and recent. It should not be biased and should reflect background cultures of English." It is very helpful to include pictures and create an interesting exercise of cultural knowledge to help students understand cultural information. Kitao stresses the importance of students' enjoyment of their textbook. "English textbooks should be useful, meaningful and interesting for students. While no single subject

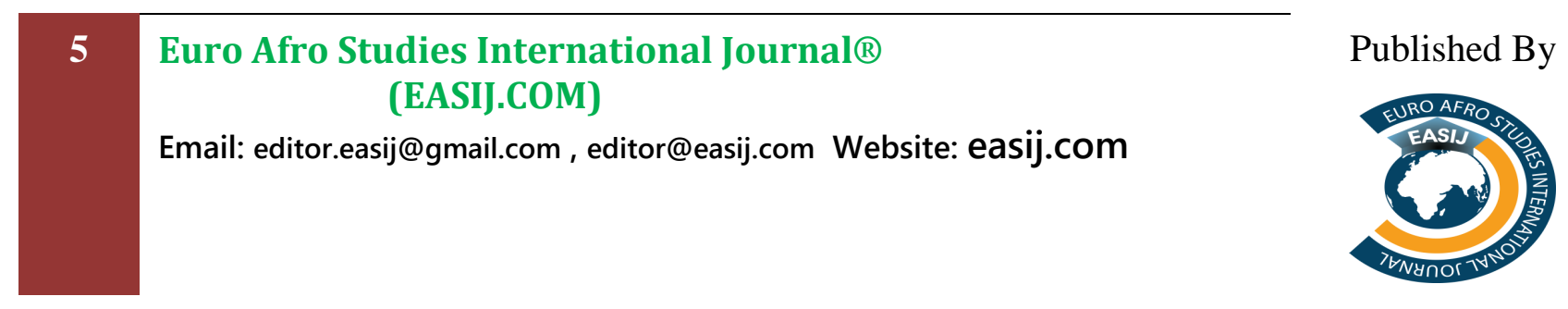


will be of interest to all students, materials should be chosen based, in part, on what students, in general, are likely to find interesting and motivating ". Another necessary factor of an English schoolbook claimed by Kitao, is that it should have clear instructional procedure and methods, that is, the teacher and students should be able to understand what is expected in each lesson and for each activity. The last necessity Kitao considers as a very important component of an English schoolbook is support for learning. "This can take the form of vocabulary lists, exercises that cover or expand on the content, visual aids and pictures."

\subsection{What do materials include?}

Kitao claims the need for schoolbooks to be the support for learning. "Schoolbooks should have support for learning. This can take the form of vocabulary lists, exercises that cover or expand on the content, visual aids, etc."

With the development of technology, photos, visual and audio materials like DVDs and computer software have become very important components of language teaching materials, and they are becoming easier to obtain. A schoolbook, equipped with a wild range of additional materials influences the content and the procedures of learning and teachers should pay much attention to what their schoolbook offers.

As a teacher - researcher who used several different English schoolbooks, I would add to all those mentioned qualities of a good English schoolbook the need of revising and using once learned and practiced items in different contexts again and again as the class work continues. Additional materials are also very helpful, as they make the learning process easier and supportive for teachers and more interesting for students. Clear structure and methodical support are the essential components of a good schoolbook. Enough communicative activities that enable students to use the language independently and that encourage work in groups or pairs should also be a matter of fact.

The claim "the study of literature is fundamentally a study of language in operation" (Widdowson: 1971) is based on the realization that literature is an example of language in use, and is a context for language use. Otherwise, studying the language of literary texts as language in operation is seen as enhancing the learner's appreciation of aspects of the different systems of language organization.

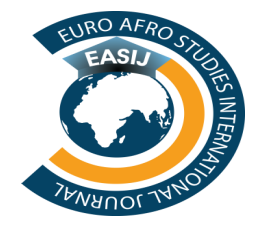


Linguistic difficulty has been one of the main arguments against literature. There has been a general pre-supposition that to study literature, one required knowledge of the intricacies of language and an inherent interpretative ability to derive the writer's message.

The advantage of using literature for the latter purpose is that literature presents language in discourse in which the parameters of setting and role-relationships are defined. R. Carter (1986) insists that a natural resolution would be to take an approach in which language and literature teaching are more closely integrated and harmonized than is commonly the case at the present time so that literature would not be isolated, possibly rejected, on account of the "literariness" of its language: It is my contention that some of the language activities and work with models on the literariness of texts can aid such development, and that responses can best develop with increased response to and confidence in working with a language using a variety of integrated activities, with language-based hypotheses and in classes where investigative, student-centered learning is the norm.

Another argument against literature also relates to literariness. With the shift to communicative approaches to ELT in the eighties, literary language is seen as not providing the conventional and appropriate kinds of language required to convey, practical, everyday messages. Poems, plays and novels make use of the same basic language system but have differing functions from non-literary discourses in the communicative function. The result is that poets, novelists and playwrights produce linguistic messages, which by their very nature, stand out prominently against the reader's background awareness of what is both communicatively conventional and linguistically appropriate to the social purpose that the message is to fulfill, though grammatically intelligible in terms of syntax and vocabulary.

Yet, what emerges from such work is the recognition that the precise contextual values of every word, phrase, clause and sentence can be inferred from its interaction with all the others in the text.

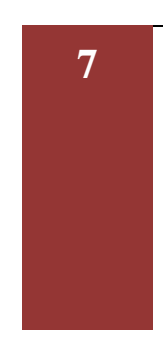

Euro Afro Studies International Journal®

(EASIJ.COM)

Email: editor.easij@gmail.com , editor@easij.com Website: easij.com

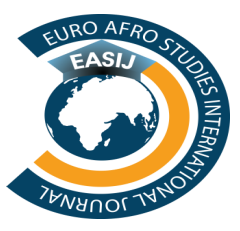




\section{RESEARCH METHODOLOGY}

3.1 Identified problems:

1. Insufficient representation of literary forms in English textbooks language;

2. Insufficient representation of literary forms in the teaching of English;

3. Absence of the required level of literacy (novel, drama, poems and short stories) in English language teaching;

4. Lack of students' required level of knowledge of literary forms.

3.2 Objectives of the research:

- To determine the representation of literary forms in English language textbooks;

- Increase the effects of applying literary forms in English language textbooks;

- To understand the need to use literary forms in English language textbooks;

- Use interactive literary models where students are active and have the opportunity to interact (dramatization, recitation).

\subsection{Research motive}

Understanding the underrepresentation of literary forms in textbooks and their inappropriate use of English language teaching served as a motive for the research. The challenges posed by the environment, new values and beliefs, and the need to modernize the educational process that need to be quantitatively implemented by implementing new quality ideas depend on how the lesson is to be delivered. The presence of literary forms in English language textbooks and their use in current education in the education system according to the curriculum and the educational framework for schools can only have a positive impact on the teaching of English.

\section{Euro Afro Studies International Journal ${ }^{\circledR}$} (EASIJ.COM)

Email: editor.easij@gmail.com , editor@easij.com Website: easij.com

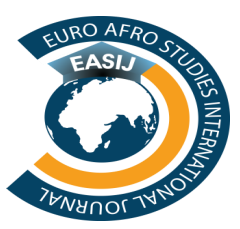




\subsection{Research Procedures and Instruments:}

\section{Statistical method}

The statistical method and its application will enable to sort and organize the previously collected data according to different criteria. All this will be supported by statistics tables and graphs to make it easier and clearer to determine the presence of literary forms in English textbooks and their effectiveness in learning English.

\section{RESEARCH ON USING LITERATURE FORMS IN THE ENGLISH LANGUAGE SCHOOLBOOKS}

The researching part of my thesis deals with the comparative point of view of the using Literature forms in the English Language Schoolbooks. Choosing two suitable English schoolbooks - Project 2 by Tom Hutchinsonand and Dream Team 3 by Norman Whitney and David Makeegan and compare them, I will summarizes the research results of the using Literature forms in these English Language Schoolbooks. Both of the textbooks are approved by the Ministry of Education.

Project 2 by Tom Hutchinsonand, third edition, Beginner - Elementary (A1-A2) level, encourages students to enjoy the process of learning, through updated content and a wealth of materials. It motivates students with engaging texts, topics, and activities across all five levels. The logical structure and clear approach provide a solid base for learning, as the course presents real language in real contexts. Expanded culture and revision sections in the new edition provide additional activities and practice for students and further resources for teachers.

Project work 2 is not a new methodology. Its benefits have been widely recognized for many years in the teaching of subjects like Science, Geography and History. Some teachers have also been doing project work in their language lessons for a long time, but for others it is a new way of working.

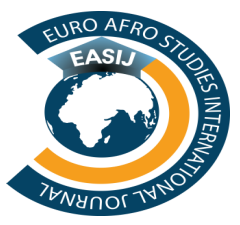


Project 2 allows students to use their imagination and the information they contain does not always have to be factual. In this example of a project which required students to introduce themselves and their favourite things.

One of the great benefits of project work is its adaptability. Each project is the result of a lot of hard work. The authors of the projects have found information about their topic, collected or drawn pictures, written down their ideas, and then put all the parts together to form a coherent presentation. Project work is not a soft option.

The project books are very creative in terms of both content and language. Each project is a unique piece of communication, created by the project writers themselves. This element of creativity makes project work a very personal experience. The students are writing about aspects of their own lives, and so they invest a lot of themselves in their project.

The schoolbook Project 2 consists eight Units divided in chapters. Making deeply research I will state that in the first Unit there are used literature forms. In the forth chapter of the first Unit, there is a part of listening about Alex Haley, a black American writer, who wrote a book about his family. The book is called Roots. There are two texts from this book that connected the students to their roots and making family tree. As task students should act as a journalists and research about Alex Haley and his book Roots.

In the second Unit, the fifth chapter is also dedicated to literature form but connected with the history. A story about The Mary rose ship that had an accident and the King Henry VIII. Students are focused on the practicing vocabulary and tenses and further in the chapter there is a text about Lifting the Mary Rose ship. Student's task is to act as a part of Mary Rose ship's equipment.

In the third Unit there is no using of literature forms.

The forth chapter of the Forth Unit of the schoolbook Project 2 is dedicated to the fairy tale of Stone soup. The use of this literature form in this chapter is focused on making delicious meals and increasing the humanity of student's mind. Student's task is to write down a meal recipe.

The fifth Unit does not content literary forms.

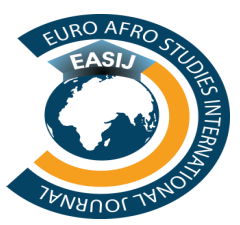


In the third chapter of the sixth Unit there is a literature form a story about The fire in London. There is also a journalistic text about The fire in London. As a task students should compare London as a city today and in the past.

The seventh Unit does not content literary forms.

In the eight Unit, the forth chapter consists a newspaper interview. This kind of literature form is used to increase the student's opinion about dialog and asking questions in appropriate way. Their task is to make an interview.

These features of project work makes it particularly well suited to the mixed ability class, because students can work at their own pace and level. The brighter students can show what they know, unconstrained by the syllabus, while at the same time the slower learners can achieve something that they can take pride in, perhaps compensating for their lower language level by using more photos and drawings.

In looking at the question of motivation, I have been most concerned with how students feel about the process of learning, that is, the kinds of activities they do in the language class. An equally important and related question is how the learners feel about what they are learning, the language. A foreign language can often seem a remote and unreal thing. This inevitably has a negative effect on motivation, because the students don't see the language as relevant to their own lives. If learners are going to become real language users, they must learn that English is not only used for talking about things British or American, but can be used to talk about their own world. Project work helps to bridge this relevance gap.

There is a growing awareness among language teachers that the process and content of the language class should contribute towards the general educational development of the learner. Project work is very much in tune with modern views about the purpose and nature of education. Connecting to independent investigation firstly, there is the question of educational values. Most modern school curricula require all subjects to encourage initiative, independence, imagination, self-discipline, co-operation, and the development of useful research skills. Project work is a way of turning such general aims into practical classroom activity.

\section{Euro Afro Studies International Journal [} (EASIJ.COM)

Email: editor.easij@gmail.com, editor@easij.com Website: easij.com

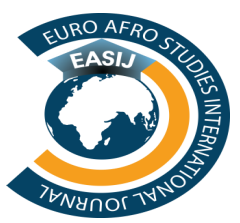


Assessment of project work is a difficult issue to tackle. This is not because project work is difficult to assess, but because assessment criteria and procedures vary from country to country. In the book is given some guidelines for assessing projects, but, of course, everyone know best what is possible in its own system.

There are two basic principles for assessing project work: Not just the language! The most obvious point to note about project work is that language is only a part of the total project. Consequently, it is not very appropriate to assess a project only on the basis of linguistic accuracy. Credit must be given for the overall impact of the project, the level of creativity it displays, the neatness and clarity of presentation, and most of all the effort that has gone into its production. There is nothing particularly unusual in this. It is normal practice in assessing creative writing to give marks for style and content, etc. Many education systems also require similar factors to be taken into account in the assessment of students' oral performance in class. So a wide-ranging 'profile' kind of assessment that evaluates the whole project is needed. If at all possible, don't correct mistakes on the final project itself, or at least not in ink. It goes against the whole spirit of project work. A project usually represents a lot of effort and is something that the students will probably want to keep. It is a shame to put red marks all over it. This draws attention to the things that are wrong about the project over the things that are good. On the other hand, students are more likely to take note of errors pointed out to them in project work because the project means much more to them than an ordinary piece of class work.

There is much more to language learning and education than just accuracy and it is a pity to make project work a hostage to accuracy-orientated assessment systems. Project work provides an opportunity to develop creativity, imagination, enquiry, and self-expression, and the assessment of the project should allow for this.

Project 2 works must rank as one of the most exciting teaching methodologies a teacher can use. It truly combines in practical form both the fundamental principles of a communicative approach to language teaching and the values of good education. It has the added virtue in this era of rapid change of being a long-established and well-tried method of teaching.

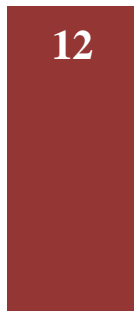

Euro Afro Studies International Journal® (EASIJ.COM)

Email: editor.easij@gmail.com , editor@easij.com Website: easij.com

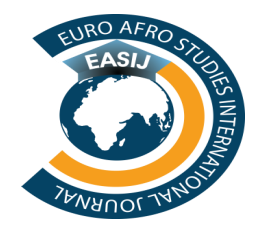


For better plasticity there is a graph showing the usage of the literature forms in the textbook Project 2 by Tom Hutchinson and, third edition, Beginner - Elementary (A1-A2) level, divided into Units:
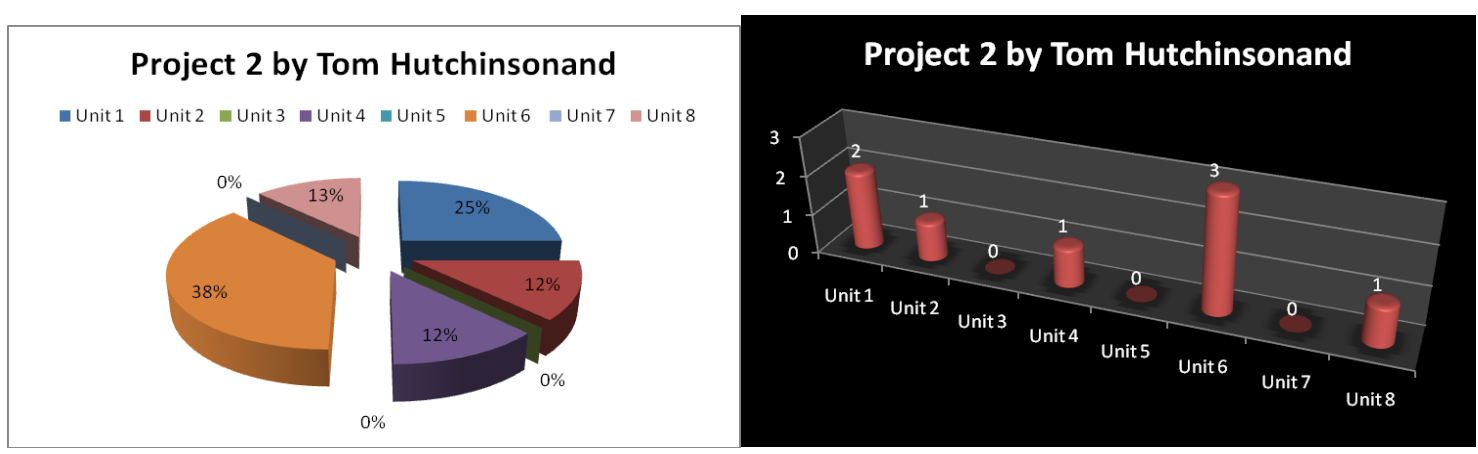

The second chosen book for comparison is Dream Team3 by Norman Whitney and David Mckeegan. Dream Team is a communicative course that teaches students how to use language in real situations, while also paying careful attention to grammar, vocabulary, and pronunciation.

It is a new lower secondary or upper primary course which is based on feedback from Open Doors users. It retains the successful Open Doors formula and methodology (i.e. reliability and clarity) together with new material and improvements.

- $\quad$ Strong emphasis is placed on the clear and thorough presentation of grammar points, followed up by systematic practice throughout the course.

- $\quad$ Plenty of practice is given from the start in reading, writing, listening, and speaking, training students to communicate fluently and effectively in English.

- $\quad$ Stimulating and engaging topics, and an amusing and lively presentation story involving the activities of teenagers, appeal directly to the age group.

- $\quad$ There is a solid built-in process of revision and consolidation, which trains students to review what they have learnt regularly and systematically, and helps them prepare for tests.

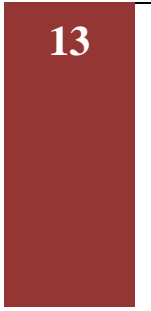

Euro Afro Studies International Journal®

(EASIJ.COM)

Email: editor.easij@gmail.com , editor@easij.com Website: easij.com

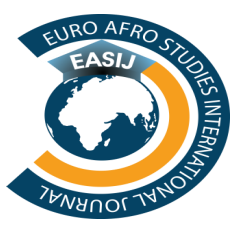


- $\quad$ The course offers a range of flexible options to help teachers meet the needs of their particular teaching situation. These include an optional introductory section, an optional final 'Bonus unit' and optional projects and stories.

Dream Team 3 contains six Units, also divided in chapters. At the end of every Unit, in the part of Listening, there is a song with a meaning connected to the Unit. Songs are a special feature for Dream Team, and are designed to consolidate the new language of each unit in a fun and lively context. They also serve as a useful introduction to English stress and rhythm. Each song is accompanied by three simple comprehension activities.

In the refreshing Unit (unit for refreshing previous knowledge) a song chapter is represented the song Dancin' in the street. Students should focus their attention on the title and why letter is missing from the first word (the final $\mathrm{g}$ in Dancing). The song is played to the students. Students should be asked (in their own language) what images the title makes them think of, e.g. a big party, a national celebration, summertime... The students should answer the exercise given in the text.

In the first Unit the song that is given is Good Thing. Students should draw attention to the title to think of a good think in their life. Students should be provoked a discussion about possible translations and decide which the best is. They should also find the examples of the present perfect. Students should also discover the mood of the song.

What have I done to deserve this is the song of the second Unit in the song chapter. Students should focus their attention on the title of the song and should explain the word deserve. The student should listen the song carefully and think about how many times they used the words what have I? Students should be asked what effect the constant repetition has (it gives the song the beat; it creates a feeling of anxiety, etc.)

In the third Unit there is a song On Broadway where the students should listen the song and answer the questions about the song (to elicit theatres, films/movies, etc). The attention should be focused on the I in the song and the students should imagine who he is, how he feels, is he happy...

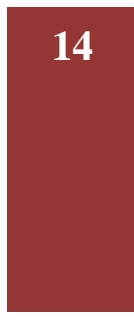

Euro Afro Studies International Journal®

(EASIJ.COM)

Email: editor.easij@gmail.com , editor@easij.com Website: easij.com

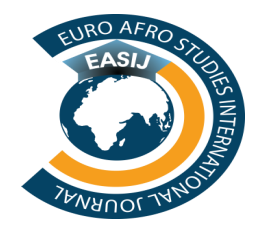


The song when will I be loved? Presented in the forth Unit the students should enjoy the tune and feel the rhythm. The attention should be drawn to the colloquial blue = unhappy and the two phrasal verbs push around $=$ take advantage (of someone) and turn down $=$ refuse, reject.

The song Sisters are doing it for themselves is part from Unit five. The students should focus their attention on who are the sisters or the possible answers. Students should also discuss who we and you refer to. Focus the students of the style of the song.

The song of the sixth Unit is Money, Money, Money. The student should focus their attention on the title and the repetition of the word Money. They should be asked if they liked the song.

To conclude, songs are useful for young students (and older students, too) because they combine the business of language learning with the pleasure of narrative, adventure, science fiction, romantic fiction, and so on. The songs of Dream Team also have strong visual appeal, and they engage the imaginative attention of the students. And since the song is recorded on cassette, they can be followed easily, even by weaker students.

For better plasticity there is a graph showing the usage of the literature forms in the schoolbook Dream Team 3 by Norman Whitney and David Mckeegan, divided into Units:

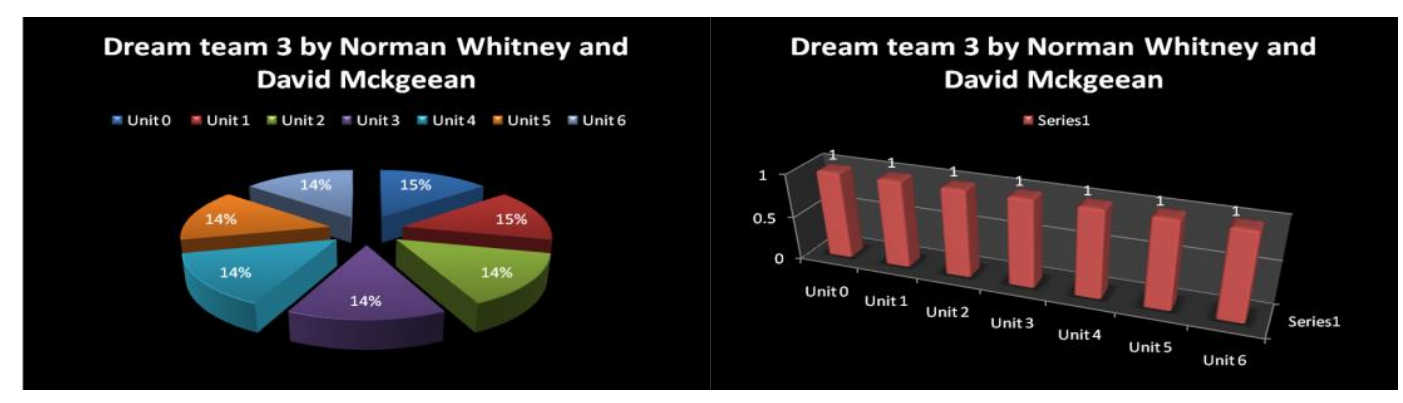

15 Euro Afro Studies International Journal ${ }^{\circledR}$

(EASIJ.COM)

Email: editor.easij@gmail.com , editor@easij.com Website: easij.com

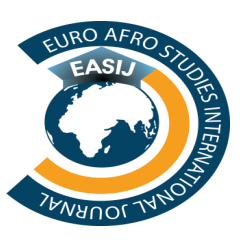




\section{COMPARISON BETWEEN THE SCHOOLBOOKS TOGETHER}

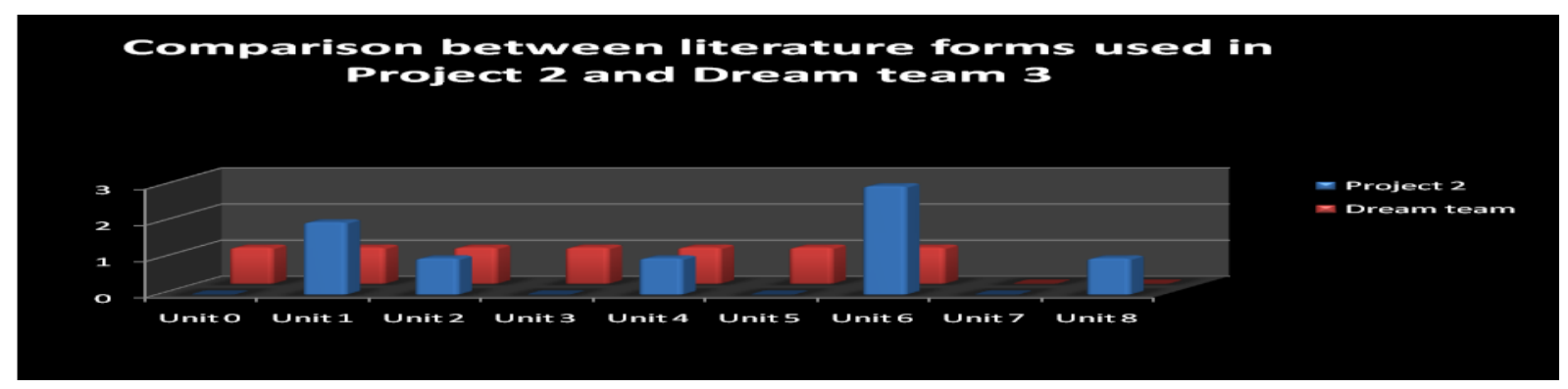

Provided that there is a satisfactory result of using literature forms in these schoolbooks, the qualities that balance between these values can be considered as very pleasing. As it is seen from the graph, in eight units of two schoolbooks gained this valuation. The teachers are also very satisfied with clear usage of the use of literature forms in textbooks with their clear structure, organization and sequence, with additional materials, with the fact that the textbooks develop a balance of all language skills, with help with preparing tests, with avoiding sexual, racial and cultural stereotypes, with clear teacher's guide with answers and help on methods and additional activities and with the creative way the textbooks follow the official syllabus.

\section{RESEARCH RESULTS}

The found (initial) situation was determined by using the procedures and instruments already described, whose focus was always on research indicators, i.e. insufficient representation of literary forms in English textbooks. When considering the use of literary forms among the textbooks from this angle, through the data obtained from the conducted procedures, it was found to be very low, and in some cases completely missing. The reason is probably the use of inappropriate teaching forms, as well as the inadequate and inadequate preparation of the teacher, who for the needs of this type of teaching (use of literary forms), should first devise and anticipate the use of forms and ways that include student learning.
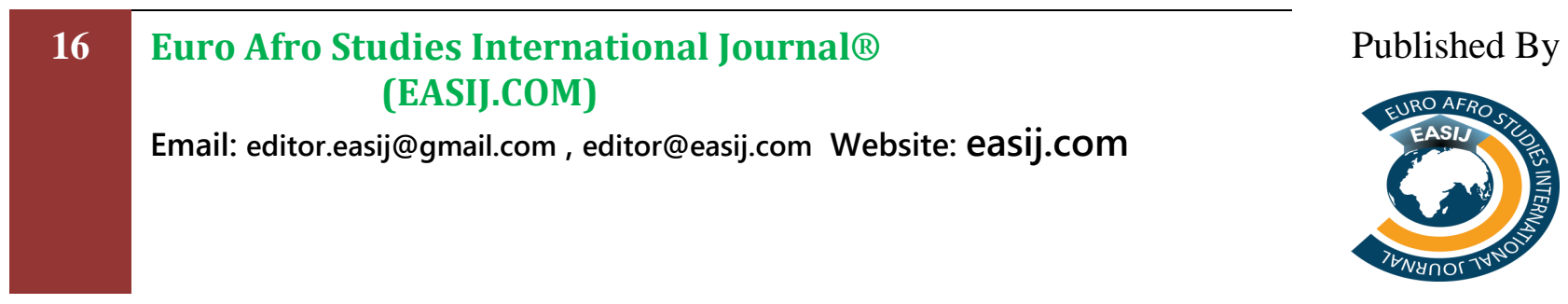


\section{CONCLUSION}

This "Using Literature forms in the English Language schoolbooks" is a concept that has its focal point in language development. Also, any syllabus based on this concept should also maintain language as the central concern. For this, it is imperative that curriculum developers depart from the traditional view attached to literature. It is also equally important that the syllabus has suggestions for teaching strategies and forms of assessment. The objectives may outline the importance of literature towards language development, but they become redundant if the teaching and assessment techniques do not apply those objectives practically.

Making the decision which schoolbook to choose for their learners is a very demanding process for teachers when they are required to make the act. Such a choice requires considering many points of view on the selection. Moreover, there are many aspects that must be considered before the best choice is made. The teacher must consider not only his/her requirements but also requirements of other teachers who will be using the same textbook, requirements of curricula and last but not least the requirements of the students themselves. To summarize the motives for selecting the best-suited textbook, it can be said that for the teachers the strongest motive was the quality of the textbook's content. The least considered motive was the financial point of view.

The two schoolbooks are attractive for students; students enjoy working with them as they provide motivating and interesting exercises. The additional materials, such as video and audiotapes, DVDs, vocabulary sets and many others were proved to be the part of the textbooks, whereas with the development of technology this support is more and more accomplished. There is a general tendency to create and use "communicative textbooks". Such textbooks are supposed to give opportunities for the students to use the language in the classroom, emphasize the communicative function of language and try to reflect the student's needs and interests; they are activity-based and have a good balance among the four language skills. This research demonstrates that the above-mentioned textbooks develop a balance of the four language skills; they follow the official syllabus in a creative manner. But there was proved a lack of more communicative activities and stimulation of the students to use the

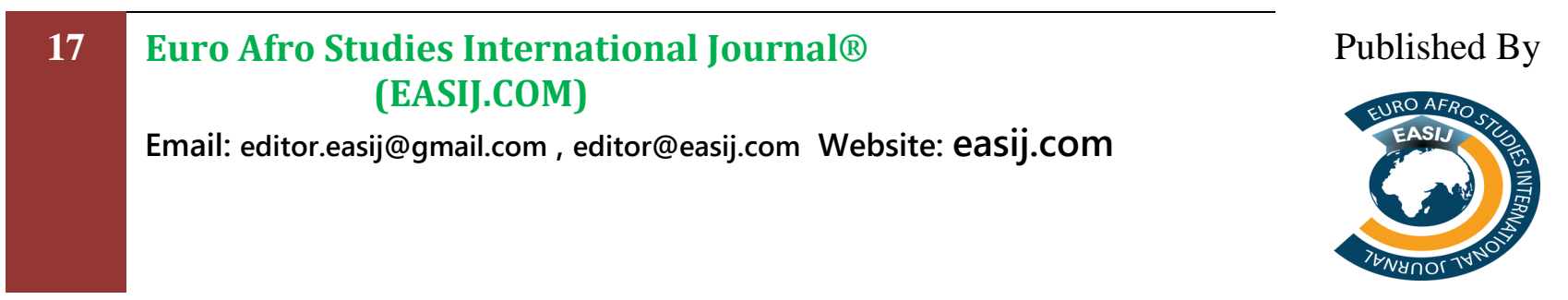


language independently, lack of practical ideas and varied practice of any set of language items.

The most frequently mentioned priority in teaching English that was stated by the teachers was communication skills and some others, for example speaking even with mistakes, willingness to learn something new, grammar, blending the language skills together etc. All of these priorities are closely connected with communication in the sense of practical use of the foreign language that leads to the ability of the students to use the language actively, ability to react, respond, understand and orientate in real situations the learners can come across. These components of a good schoolbook were not found to the full satisfactory in this research, the teachers proved their lack. Listening activities were proved to be the most important for the teachers if they could choose the best-suited textbook. The call for listening activities shows the need for the above-mentioned communicative skills as these activities are based on an active using of a language in different contexts.

If we want to do the textbooks better in future, we must be aware of the textbooks imperfections, of the missing components that are claimed by the teachers who actively use the textbook for some years. The creators of new textbooks should be in contact with those teachers and continuously check their claims, reminders and suggestions and use the findings to create the most perfect textbook they can.

To conclude what I mentioned in the introduction was that my aim in this seminar paper was to present the general view of using Literature forms in English language schoolbooks, Dream Team 3 and Project 2, and I suppose that I did it. I have also stated that although the studies on the use of literature forms in teaching English have been increasing abroad, in our country, particularly in public schools, only English grammar is being taught. The students who are expected to memorize these rules cannot use English. The aim of this seminar paper was to exhibit why and how literature forms can be used in order to teach English effectively and efficiently.

18

Euro Afro Studies International Journal ${ }^{\circledR}$ (EASIJ.COM)

Email: editor.easij@gmail.com , editor@easij.com Website: easij.com
Published By

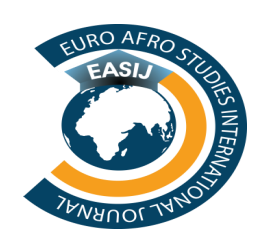




\section{References}

Byard, Patricia. Textbooks: Evaluation for Selection and Analysis for Implementation. In M. Celce-Murcia (Ed.), Teaching English as a second or foreign language (pp. 415-427). Boston, MA: Heinle \& Heinle Publishers, a division of Thomson Learning, 2001

Carter, R \& Long, M. (1991). Teaching Literature, Longman

Carter, R. \& McRae, J. (eds.), (1996). Language, Literature and the Learner. Harlow: Addison Wesley Longman.

Carter, R. and Long, M. (1991). Teaching literature. London: Longman.

Collie, J. and S. Slater. 1990. Literature in the Language Classroom: A Resource Book of Ideas and Activities. Cambridge: CUP.

Cook, G. (2000). Language Play, Language Learning, Oxford University Press: Oxford

Damen, L. 1987. Culture Learning: The Fifth Dimension on the Language Classroom. Reading, MA: Addison-Wesley. Culture Learning: The Fifth Dimension on the Language Classroom. Reading, MA: Addison-Wesley.

Finney, D. (2002). The ELT curriculum: a flexible model for a changing world. In Richards, J. C. \& Renandya, W. A. (Eds). Methodology in language teaching (pp. 69-79). Cambridge: Cambridge University Press.

Flower, Linda, and John R. Hayes. (1981) "A Cognitive Process Theory of Writing." College Composition and Communication.

19 Euro Afro Studies International Journal ${ }^{\circledR}$ (EASIJ.COM)

Email: editor.easij@gmail.com , editor@easij.com Website: easij.com

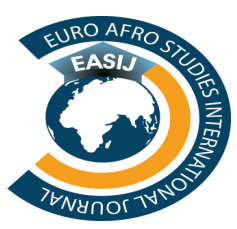


Ganakumaran, S. (2003). Literature programmes in Malaysian schools: A historical overview. In Ganakumaran, S. (ed.). Teaching of literature in ESL/EFL contexts. Petaling Jaya: Sasbadi Sdn. Bhd., 27-48.

Goodman, K. (1970). Reading as a psychologistic guessing game. In H. Singer and R. b. Ruddell. (eds.). Theoretical models and Processes of Reading. Newark, N. J.: International Peading Association.

Grant, N. Making the most of your textbook, Essex, England, Longman Group UK Limited, 1987.

Hutchinsonand, Tom. (1995) “Project 2". Oxford University Press

Kenji Kitao S. Kathleen Kitao. "Selecting and developing Teaching/Learning materials“. The Internet TESL Journal. IV, No. 4, (1997) URL:?http://www.iteslj.org/Articles/KitaoMaterials.html目.

Short, M. (1986) "Teaching Study Skills for English literature" in R.Carter \& C.J.Brumfit (ed) Literature and Language teaching. Oxford: OUP.

Whitney, Norman and Makeegan, David. (2001) “Dream Team 3". Oxford University Press

Widdowson, H.G. (1975) Stylistics and the teaching of literature London: Longman.

20 Euro Afro Studies International Journal@ (EASIJ.COM)

Email: editor.easij@gmail.com , editor@easij.com Website: easij.com

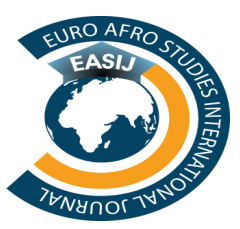




\section{Cite this article:}

Author(s), Sashka Jovanovska (2019). "Language teaching and testing - a research of using lliterature forms in the English Language Schoolbooks", Name of the Journal: Euro Afro Studies International Journal, (EASIJ.COM), P, 27 - 47. DOI: 10.5281/zenodo.3565842, Issue: 1, Vol.: 1, Article: 2, Month: December, Year: 2019. Retrieved from https://www.easij.com/allissues/

\section{Published by}

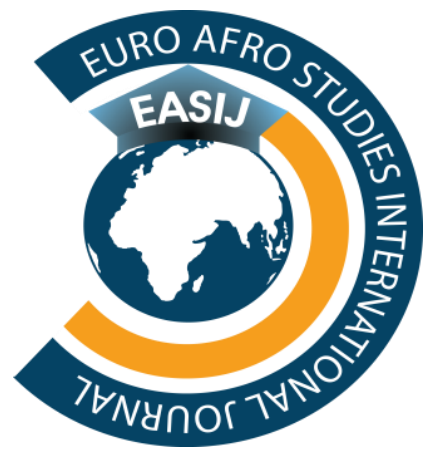

21 Euro Afro Studies International Journal ${ }^{\circledR}$ Published By (EASIJ.COM)

Email: editor.easij@gmail.com , editor@easij.com Website: easij.com

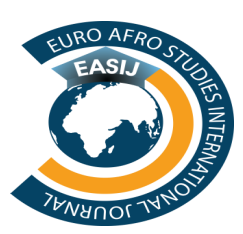


o $\quad$ Euro Afro Studies International Journal@ (EASIJ.COM)

Email: editor.easij@gmail.com , editor@easij.com Website: easij.com

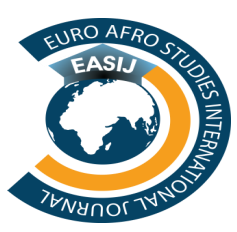

